\title{
Pengaruh Panjang Pengupasan Terhadap Sensitivitas dan Akurasi Sensor Gula Darah Menggunakan Serat Optik Singlemode
}

\author{
Resti Novirza*, Muldarisnur \\ Jurusan Fisika FMIPA, Universitas Andalas, Padang \\ *restinovirza595@yaoo.com
}

\begin{abstract}
ABSTRAK
Telah dilakukan optimasi panjang pengupasan sensor serat optik singlemode untuk memperoleh sensitivitas dan akurasi yang tinggi pada sensor pengukuran gula darah. Panjang pengupasan divariasikan antara $1 \mathrm{~cm}$ hingga $5 \mathrm{~cm}$ dengan interval $1 \mathrm{~cm}$. Serat optik digunakan untuk memandu cahaya dari sumber laser dioda merah $(\lambda=650 \mathrm{~nm})$ ke detektor fotodioda. Interaksi antara gelombang evanescent dan molekul glukosa dalam darah meningkat karena sebagian cladding pada serat optik dikupas. Perbedaan kedalaman penetrasi karena panjang pengupasan mempengaruhi sensitivitas dan akurasi sensor yang telah dirancang. Sensitivitas tertinggi yaitu $1,034 \mathrm{mV} /(\mathrm{mg} / \mathrm{dL})$ yang diperoleh pada panjang pengupasan $3 \mathrm{~cm}$. Sensitivitas terendah diperoleh pada panjang pengupasan $5 \mathrm{~cm}$ dengan nilai $0,453 \mathrm{mV} /(\mathrm{mg} / \mathrm{dL})$. Akurasi tertinggi terdapat pada panjang pengupasan $2 \mathrm{~cm}$ dengan nilai 95,23\% dan akurasi terendah pada panjang pengupasan $1 \mathrm{~cm}$ dengan nilai 93,35\%. Clark Error Grid Analisis menunjukkan bahwa data tersebar 95\% di daerah A dan 0,5\% di daerah B yang mempenyai error yang kecil, artinya optimasi sensor gula darah akurat dan dapat diandalkan.
\end{abstract}

Kata kunci: sensor gula darah, gelombang evanescent, panjang pengupasan, sensitivitas, akurasi.

\begin{abstract}
The optimization of the singlemode optical fiber sensor has been carried out to obtain high sensitivity and accuracy on the sensor for measuring blood sugar. The length of stripping is varied from $1 \mathrm{~cm}$ to $5 \mathrm{~cm}$ at intervals of $1 \mathrm{~cm}$. Optical fiber is used to gude light from a red diode laser source $(\lambda=650 \mathrm{~nm})$ to a photodiode detector. The interaction between evanescent waves and glucose molecules in the blood increases because some of the cladding on optical fibers is peeled. Differences in penetration depth because of the length of stripping affect the sensitivity and accuracy of the sensors that have been designed. The highest sensitivity is $1.034 \mathrm{mV} /(\mathrm{mg} / \mathrm{dL})$ obtained at the stripping length of $3 \mathrm{~cm}$. The lowest sensitivity was obtained at the stripping length of $5 \mathrm{~cm}$ with a value of $0.453 \mathrm{mV} /(\mathrm{mg} / \mathrm{dL})$. The highest accuracy is found in the stripping length of $2 \mathrm{~cm}$ with a value of $95.23 \%$ and the lowest accuracy at the stripping length of $1 \mathrm{~cm}$ with a value of $93.35 \%$. Clark Error Grid Analysis shows that data is $95 \%$ spread in area $A$ and $0.5 \%$ in area $B$ which has a small error, meaning that blood sugar sensor optimization is accurate and reliable.

Keywords: blood sugar sensor, evanescent wave, stripping length, sensitivity, accuracy.
\end{abstract}

\section{PENDAHULUAN}

Diabetes melitus merupakan suatu penyakit kronik dimana tubuh tidak dapat memproduksi insulin atau tidak dapat menggunakan insulin secara efektif (IDF, 2013). Diabetes merupakan salah satu penyakit dengan jumlah penderita terbanyak di dunia. Data IDF tahun 2017 menunjukkan jumlah penderita diabetes di Indonesia pada tahun 2017 mencapai 10 juta jiwa dan diperkirakan meningkat hingga 22 juta jiwa pada Tahun 2040.

Diabetes dapat disebabkan oleh produksi insulin yang tidak mencukupi atau kualitas insulin yang dihasilkan kurang memadai. Ketiadaan insulin menyebabkan tubuh tidak dapat mengubah glukosa menjadi energi, akibatnya terjadi penumpukan glukosa didalam darah. Diabetes diindikasikan oleh tingginya kadar gula darah disertai dengan berat badan turun, luka yang susah sembuh dan sering buang air kecil. Komplikasi diabetes mellitus dapat dibedakan atas komplikasi akut dan komplikasi kronis. Komplikasi akut dapat menyebabkan sel - sel otak tidak mendapat pasokan energi sehingga tidak berfungsi bahkan mengalami kerusakan. Komplikasi kronis dapat menyebabkan pembekuan darah pada sebaian otak, penyakit jantung koroner, gagal jantung dan stroke. Disamping dampak kesehatan, biaya yang dibutuhkan oleh pasien diabetes juga sangat tinggi.

Pengukuran kadar gula darah dapat dilakukan dengan menggunakan dua metode, yaitu dengan invasive dan non-invasive. Pengukuran kadar gula darah secara invasive umumnya menggunakan sampel darah. Pengambilan sampel darah dengan tusukan jarum mengakibatkan 
terjadinya infeksi. Hal ini mendorong dikembangkannya metode lain yang lebih efektif dan tanpa efek samping. Pengukuran kadar gula secara non-invasive biasanya dilakukan menggunakan sampel urine, air ludah, keringat, dan air mata.

Ada beberapa metode non-invasive untuk pengukuran kadar gula seperti spektroskopi Inframerah dan spektroskopi Raman. Spektroskopi inframerah adalah metode identifikasi senyawa kimia berdasarkan frekuensi getaran molekul. Pada spektroskopi inframerah, cahaya inframerah dekat hanya menembus setengah milimeter dibawah kulit, sehingga mengukur jumlah glukosa dalam sel instertitial, bukan jumlah dalam darah. Pengukuran dengan spektroskopi Raman dapat dilakukan langsung pada cairan tubuh, namun kurang efisien digunakan karena pengukuran membutuhkan waktu yang lama akibat rendahnya intensitas hamburan tak elastisnya (Ellis, 2006).

Metode non-invasive menggunakan sampel urine pertama kali dilakukan pada tahun 1941 oleh Walter Ames Compton. Compton melakukan pengukuran dengan melihat perubahan warna pada urine yang telah direaksikan dengan larutan benedict. Cara ini memiliki kelemahan karena tidak menunjukkan nilai kadar gula darah sebenarnya sehingga kurang akurat untuk digunakan oleh penderita diabetes. Pengukuran kadar gula darah menggunakan urine secara lebih kuantitatif dapat dilakukan dengan mengukur intensitas cahaya yang diteruskan setelah melewati sampel urine.

Saylendra (2009) telah mengukur kadar gula darah menggunakan urine melalui pelemahan intensitas cahaya yang dideteksi oleh sensor LDR (Light-Dependent Resistor). Hasil pengukuran ditentukan oleh penempatan sumber cahaya dan detektor. Satria (2013) yang juga menggunakan sensor LED infrared dan foto dioda. Satria melakukan penelitian secara kualitatif karena dikonversi dari perubahan warna. Pada penelitian Saylandra (2009) dan Satria (2013), posisi sumber cahaya terhadap fotodetektor sangat berpengaruh terhadap keakuratan penelitian. Akibatnya, hasil pengukuran kurang tepat jika posisi sumber cahaya berubah sedikit saja.

Serat optik multimode sering digunakan karena memiliki diameter core besar sehingga cahaya dari sumber mudah dilewatkan keserat optik. Banyaknya gelombang yang dipandu oleh serat optik multimode akan saling berinteraksi sehingga terjadi pelemahan sinyal. Pada penelitian ini akan dikembangkan sensor serat optik singlemode untuk mengukur kadar gula darah secara non-invasive melalui urine. Serat optik singlemode memiliki inti yang jauh lebih kecil yang hanya memungkinkan satu mode cahaya saja terpandu di dalam inti (core) sehingga tidak terjadi interaksi antar modus terpandu (dispersi) sehingga diharapkan lebih sensitif dan akurat dibandingkan serat optik multimode.

\section{METODE}

Sensor pengukuran kadar gula darah dibuat menggunakan fotodioda, laser dioda $(\lambda=650 \mathrm{~nm})$, microcontroler arduino UNO dan LCD. Sampel urine pasien diambil di rumah sakit Dr. Reksodiwiryo.

\subsection{Karakterisasi Sistem Sensor Serat Optik}

Karakterisasi sensor serat optik diawali dengan melihat tegangan keluaran fotodioda ketika karakterisasi tegangan terhadap korelasi glukosa ke fotodioda tanpa serat optik divariasikan. Tegangan keluaran makin besar dengan meningkatnya intensitas cahaya, sehingga diperlukan rangkaian pembagi tegangan pada fotodioda (Malvino, 1985).

Sensor yang dirancang menggunakan serat optik sepanjang $21 \mathrm{~cm}$. Modifikasi dilakukan dengan cara mengupas coating serat optik dengan cutter sepanjang 1-5 cm. Cladding yang berupa selaput, dikelupas dengan cara mengikis permukaan serat optik atau melepaskannya secara perlahan. Pengikisan dilakukan dengan menggunakan ampelas yang nomor 3, pengikisan ini dibantu dengan larutan aseton. Pengikisan dilakukan secara perlahan dan searah sampai terdapat indikasi cladding terlepas. Indikasi terlepasnya cladding dapat diketahui ketika sudah terdapat kebocoran daerah sensing apabila dilalui cahaya, dimana hal ini dapat terlihat dengan mata dan juga diuji dengan BF5R (Sensor serat optik digital) (Topan dan Harmadi, 2014). Serat optik yang telah dikelupas lalu diuji dengan BF5R untuk melihat 
responnya menggunakan variasi zat cair sebagai cladding pengganti. Selanjutnya, sensor serat optik dikarakterisasi dengan variasi panjang pengupasan.

\subsection{Pembuatan Spesimen Urine}

Spesimen uji dari perancangan alat ukur kadar gula darah non-invasive ini dibuat dengan mereaksikan 8 sampel urine penderita yang memiliki tingkat gula pereduksi berbedabeda dengan larutan sulfat tembaga yaitu larutan Benedict. Pendeteksian gula dalam urine dengan prosedur copper reduction test dapat dilakukan dengan mereaksikan urine dan larutan Benedict dimana setiap satu tetes urine direaksikan dengan lebih kurang $1 \mathrm{~mL}$ larutan Benedict (King, 2008). Campuran urine dengan larutan Benedict ini kemudian dipanaskan dengan menggunakan lampu spiritus. Setelah dipanaskan, lalu spesimen dipasang pada sistem alat yang sudah dirancang. Pemanasan spesimen idealnya dilakukan selama 30 detik yaitu sesaat setelah spesimen mendidih agar reaksi reduksi tidak terjadi secara berlebihan (Satria dan Wildian, 2012).

\subsection{Pengumpulan Data dan Pengujian Alat Keseluruhan}

Pengujian sistem pengukuran kadar gula darah ini diawali dengan melakukan pengujian pada rangkaian sumber tegangan, mikrokontroler arduino UNO untuk melihat ADC arduino UNO, setelah itu mengkarakterisasi sistem sensor serat optik. Lalu, spesimen urine diletakkan pada alat yang telah dinyalakan dan sensor serat optik aktif maka alat ukur bekerja, sehingga data keluaran dari alat ukur akan ditampilkan pada LCD berupa nilai kadar gula darah (mg/dL).

\section{HASIL DAN DISKUSI}

\subsection{Karakterisasi Sensor Serat Optik}

Karakterisasi sistem sensor serat optik dapat dilakukan dengan melihat hubungan tegangan keluaran fotodioda dengan kadar gula darah sampel urin. Plot tegangan keluaran fotodioda sebagai fungsi kadar gula darah beberapa variasi panjang pengupasan untuk serat optik lurus ditampilkan pada Gambar 1. Data yang ditampilkan adalah nilai rata-rata dan standar deviasi dari tiga pengukuran berulang.

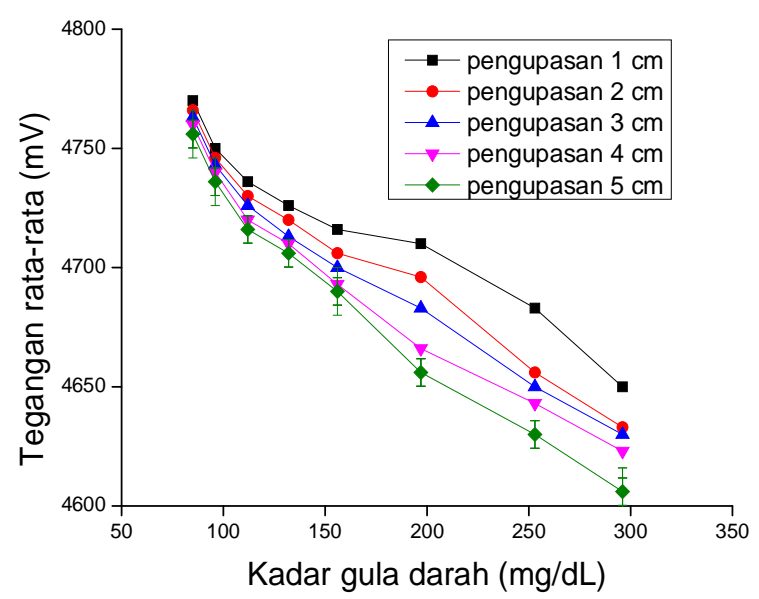

Gambar 1 Tegangan keluaran fotodioda pada sistem sensor serat optik lurus sebagai fungsi kadar gula darah untuk panjang pengupasan $1 \mathrm{~cm}-5 \mathrm{~cm}$

Tegangan keluaran berkurang dengan meningkatnya kadar gula darah disebabkan oleh makin besarnya atenuasi gelombang terpandu oleh molekul glukosa akibat bertambahnya kedalaman penetrasi gelombang evenescent. Kedalaman penetrasi bertambah dengan semakin kecilnya selisih antara indeks bias core dengan urin. Nilai tegangan kadar gula darah menurun seiring dengan bertambahnya kadar gula darah. Hal ini disebabkan oleh semakin berkurangnya intensitas yang terpandu di dalam serat optik akibat dari banyaknya molekul glukosa yang diserap di dalam serat optik sehingga terjadi atenuasi (pelemahan) gelombang terpandu. 


\subsection{Sensitivitas Sensor}

Sensitifitas akan menunjukkan seberapa tepat kepekaan sensor serat optik terhadap sampel yang diukur. Sensitivitas sensor kadar gula darah dipengaruhi oleh panjang pengupasan. Sensitivitas sensor menunjukkan laju penurunan tegangan keluaran fotodioda terhadap kadar gula darah akibat atenuasi gelombang terpandu dalam serat optik oleh molekul glukosa. Nilai sensitivitas dipengaruhi oleh panjang pengupasan tetapi dalam rentang nilai yang kecil. Nilai sensitivitas tertinggi pada panjang pengupasan $3 \mathrm{~cm}$ dengan nilai $1,034 \mathrm{mV} /(\mathrm{mg} / \mathrm{dL})$ sedangkan nilai sensitivitas terendah pada panjang pengupasan $5 \mathrm{~cm}$ dengan nilai $0,453 \mathrm{mV} /(\mathrm{mg} / \mathrm{dL})$.

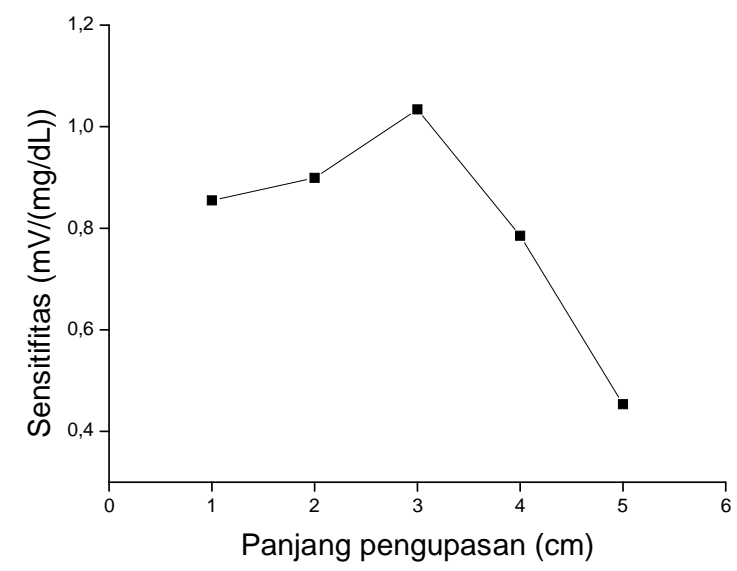

Gambar 2 Grafik sensitivitas sensor kadar gula darah dengan serat optik lurus sebagai fungsi panjang pengupasan

\subsection{Akurasi Data Pengukuran}

Perhitungan data penelitian sangat diperlukan untuk melihat keakuratan data yang diperoleh dalam penelitian. Kadar glukosa urine diukur sebanyak tiga kali untuk setiap pengukuran. Dari hasil didapatkan nilai akurasi hampir tidak bergantung pada panjang pengupasan karena selisih yang didapat sangat kecil yaitu antara 1\%-3\%. Secara umum hasil akurasi yang didapatkan sudah cukup tinggi namun belum mencapai keakuratan $100 \%$, karena pada saat pengukuran tidak diberikan pembatas antara sensor gelombang evenescent dengan sampel urine.

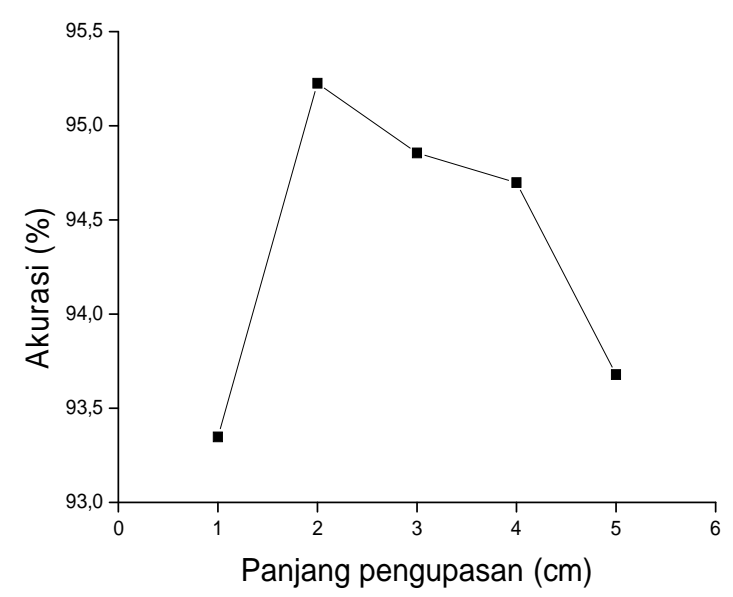

Gambar 3 Grafik hubungan akurasi sensor lurus untuk setiap panjang pengupasan 


\subsection{Clark Error Grid Analysis}

Grafik CEG digunakan untuk menguji apakah nilai kadar gula darah yang didapatkan dalam pengukuran akurat atau tidak. Gambar di atas menampil nilai validasi hasil pengukuran kadar gula darah dengan warna yang berbeda, warna yang berbeda tersebut merupakan nilai dari panjang pengupasan sedangkan bentuk yang berbeda merupakan nilai dari variasi bending yang diberikan. Data pengukuran menggunakan sensor serat optik singlemode tersebar 95\% di daerah A dan $0,5 \%$ di dearah B. Hal ini membuktikan alat ukur yang dihasilkan sangat akurat dan hasil pengukuran kadar gula darah yang dihasilkan sangat baik.

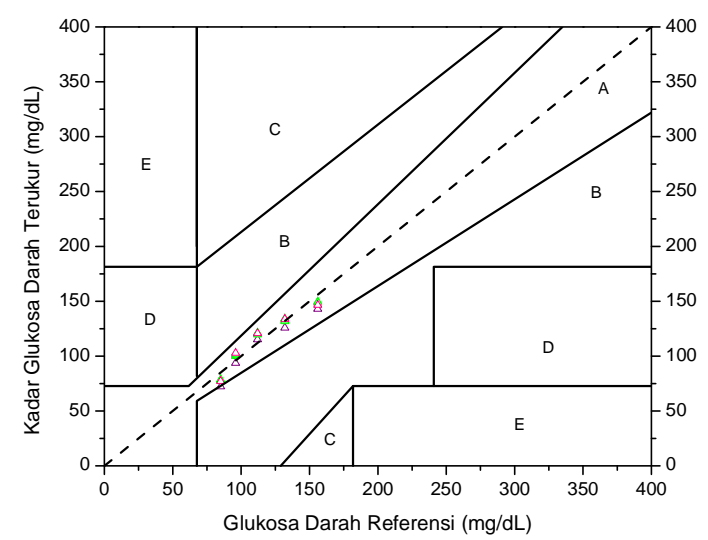

Gambar 4 Grafik validasi pengukuran kadar gula darah oleh sensor serat optik lurus

\section{KESIMPULAN}

Tegangan keluran sensor serat optik sangat bergantung terhadap panjang pengupasan, semakin besar panjang pengupasan maka tegangan keluaran yang dihasilkan akan semakin kecil. Nilai sensitivitas tertinggi yaitu pada panjang pengupasan $3 \mathrm{~cm}$ dengan nilai 1,034 $\mathrm{mV} /(\mathrm{mg} / \mathrm{dL})$ sedangkan sensitivitas terendah pada panjang pengupasan $5 \mathrm{~cm}$ dengan nilai 0,543 $\mathrm{mV} /(\mathrm{mg} / \mathrm{dL})$. Nilai sensitivitas bergantung pada panjang pengupasan (L), semakin besar panjang pengupasan maka nilai sensitivitas juga akan semakin besar. Pemberian panjang pengupasan maksimum untuk pengukuran kadar gula darah dengan menggunakan serat optik singlemode yaitu $3 \mathrm{~cm}$. Nilai akurasi sensor serat optik hampir tidak bergantung terhadap panjang pengupasan karena selisih yang didapatkan hanya $1 \%-3 \%$.

\section{DAFTAR PUSTAKA}

Agrawal, G.P., 2002, Fiber Optic Communication System, Edisi Ketiga, Wiley-Interscience, New York.

Akhbar, Z., 2014, Rancangan Prototype Instrumen Ukur Kadar Gula Darah dengan Metode Pengenalan Warna dan Tingkat Kekeruhan Urine dalam Uji Benedict Berbasis Visual Basic.NET, Skripsi, Program Pascasarjana Universitas Jember, Jember.

Benedict, S.R., 1907, The Detection and Estimation of Reducing Sugars, Journal of Biological Chemistry, Vol. 3, hal 101-117.

Ellis, D.I., Goodacre, R., 2006, Metabolic Fingerprinting in Disease Diagnosis: Biomedical Application of Infrared and Raman Spectroscopy, Analyst Journal, Vol.131, hal.875885 .

Fridayanti, N., Muldarisnur, M., Harmadi, H,. 2018 Analisis Pengaruh Macrobending Serat Optik Pada sensor Glukosa Dengan Metode Evanescent, Jurnal Ilmu Fisika, Vol. 10 no. 1, p.46-52.

International Diabetes Federation, 2017, IDF Diabetes Atlas, Edisi 8, Brussel, Belgium.

Kim, Y.J. dan Yoon, G., 2006, Prediction of Glucose in Whole Blood by Near-Infrared Spectroscopy: Influence of Wavelength Region, Prepocessing, and Hemoglobin Concentration, Journal Biomed, No.4, Vol.11.

Prasetya, D., 2009, Serat Optik, Skripsi, Universitas Sriwijaya, Palembang. 